\title{
The Effects of Brown Algae-Derived Monosaccharide L-Fucose on Lipid Metabolism in C57BL/6J Obese Mice
}

\author{
Xiao Yuan ${ }^{1}{ }^{1}$, Tomohiko Nakao ${ }^{1}$, Hina Satone ${ }^{1}$, Kazuyuki Ohara ${ }^{1}$, Yuri Kominami ${ }^{1}$, Miho Ito ${ }^{2}$, \\ Teruki Aizawa ${ }^{2}$, Tomoya Ueno ${ }^{2}$ and Hideki Ushio ${ }^{1, *}$ \\ 1 Department of Aquatic Bioscience, Graduate School of Agricultural and Life Sciences, University of Tokyo, \\ Tokyo 113-8657, Japan; yuanxiao_bruce@foxmail.com (X.Y.); nakao-tomohiko839@g.ecc.u-tokyo.ac.jp (T.N.); \\ asatone@mail.ecc.u-tokyo.ac.jp (H.S.); ohr@showagakuin.ac.jp (K.O.); akomi@mail.ecc.u-tokyo.ac.jp (Y.K.) \\ 2 Yaizu Suisankagaku Industry Co., Ltd., 5-8-13 Kogawa-shimmachi, Yaizu, Shizuoka 425-8570, Japan; \\ mi-ito@yskf.co.jp (M.I.); t-aizawa@yskf.co.jp (T.A.); t-ueno@yskf.co.jp (T.U.) \\ * Correspondence: aushio@mail.ecc.u-tokyo.ac.jp; Tel.: +81-3-5841-7520
}

Received: 30 October 2020; Accepted: 9 December 2020; Published: 11 December 2020

check for updates

\begin{abstract}
Obesity is a global public health problem and a risk factor for several metabolic disorders as well as cancer. In this study, we investigated the effects of L-fucose on lipid metabolism through chronic and acute in vivo experiments in mice. In the chronic test, mice were fed a high-calorie diet (HCD) containing $0.0001 \%, 0.001 \%, 0.01 \%$, and $0.1 \%$ L-fucose for one month. The L-fucose supplementation inhibited body weight and visceral fat mass gain in HCD-fed mice. The results of the acute test showed that L-fucose increased the ratio of serum high molecular weight adiponectin and enhanced glucose and lipid catabolism. Furthermore, L-fucose also decreased the expression of adipogenic genes (peroxisome proliferator-activated receptor $\gamma$ and cluster of differentiation 36). In conclusion, this study provides a new approach to combat obesity and the related diseases.
\end{abstract}

Keywords: L-fucose; intra-abdominal fat; obesity; adipogenesis; metabolic diseases

\section{Introduction}

Obesity, characterized by excessive fat accumulation in the body, is a chronic disease and a global public health problem. This disease is closely related to genetic, endocrine, and psychological factors, as well as poor diets. Obesity is also widely regarded as a risk factor for various chronic metabolic diseases including type 2 diabetes, dyslipidemia, hyperglycemia, and/or hypertension [1]. Furthermore, obesity can also cause musculoskeletal disorders and increase the risk of cancers such as colorectal, breast, and endometrial cancer [2].

The adipose tissue secretes various adipokines to maintain metabolic homeostasis. Obesity is associated with dysregulated secretion of adipokines [3]. Adiponectin is an adipokine that enhances insulin sensitivity and stimulates fatty acid oxidation by promoting the AMP-activated protein kinase (AMPK) pathway [4]. The AMPK signaling pathway is considered a physiological energy control system [5]. Plasma adiponectin levels are decreased in the state of obesity and insulin resistance in high-fat diet-induced obese mice [6]. In the serum, there are three types of adiponectin oligomeric complexes, including trimer (low molecular weight, LMW, $67 \mathrm{kDa}$ ), hexamer (medium molecular weight, MMW, $140 \mathrm{kDa}$ ), and multimer (high molecular weight, HMW > $300 \mathrm{kDa}$ ) [7,8]. High molecular weight adiponectin is considered the most biologically active form [9]. A reduction in HMW adiponectin increases the risk of metabolic syndrome, a metabolic disorder associated with obesity, hyperlipidemia, diabetes, etc. $[10,11]$. Peroxisome proliferator-activated receptor $\gamma(\operatorname{PPAR} \gamma)$ and cluster of differentiation 
36 (CD36) are two important lipid metabolism-related genes that affect the cellular uptake of fatty acids and adipocyte differentiation [12,13].

Seaweeds are a crucial part of marine ecosystems and living resources. In recent years, numerous bioactive compounds have been isolated from different seaweed species, such as fatty acids, sterols, carotenoids, and polysaccharide dietary fibers. The presence of various bioactive compounds in seaweeds makes them highly applicable in the food supplement industries [14]. L-fucose is a hexasaccharide deoxysugar with the chemical formula C6H12O5, lacking oxygen at carbon 6 in the galactose. It is a structural monosaccharide from the brown algal polysaccharide, fucoidan. Fucoidan is an L-fucose-containing sulfated polysaccharide (FCSP), which can be extracted from the cell walls of brown algae species such as Laminaria and Sargassum [15]. Kim et al. reported that brown algae-derived fucoidan exhibits anti-obesity effects and inhibits fat accumulation in high-fat diet-induced obese mice [16]. Fucoidan also inhibits the differentiation of 3T3-L1 adipocytes [17]. It has been shown that L-fucose effectively improves obesity caused by a high-fat diet in mice [18] and cannot be metabolized as a source of energy [19]. The specific molecular mechanisms underlying the anti-obesity effects of L-fucose have not yet been fully elucidated. Since fucoidan is a heteropolysaccharide, the monosaccharide composition and sequences drastically affect its functional properties [20], rendering the quantitative control of its effects during application challenging. However, the fucoidan-derived monomer L-fucose is suitable as a functional food use because of its relatively high chemical stability and applicability in a purified form. Moreover, L-fucose is presumably safe for human oral administration, since human babies ingest monosaccharides via breast milk [21].

Male C57BL/6J mice have been reported to be more susceptible to visceral obesity compared to females [22]. Therefore, we selected male C57BL/6J as the animal model for research on obesity. The present study was designed to investigate the potential benefits of L-fucose on body weight in high-calorie diet-induced obese mice through an in vivo chronic test. Furthermore, the molecular mechanisms including obesity-related genes were also evaluated through an in vivo acute test to advance the understanding of the beneficial effects of L-fucose on obesity.

\section{Materials and Methods}

\subsection{Animals and Diets}

Six-week-old C57BL/6JJcl male mice (approximately $20 \mathrm{~g}$ in body weight, CLEA, Tokyo, Japan) were housed in a temperature and humidity-controlled laboratory animal room and entrained to a $12 \mathrm{~h}$ light-dark cycle with food and clean water available ad libitum.

For the chronic test, the American Institute of Nutrition-93 purified diets (AIN-93) were used as the basic diet. The high-calorie diet (HCD) contained 20\% casein, 20\% $\alpha$-cornstarch, 9.625\% $\beta$-cornstarch, $5 \%$ cellulose, $10 \%$ sucrose, $30 \%$ soybean oil, $1 \%$ AIN-93 vitamin mix, 3.5\% AIN-93 mineral mix, $0.375 \%$ L-cystine, and $0.5 \%$ choline chloride (Oriental Yeast, Tokyo, Japan). The lipid ratio of this composition was $30 \%$. The specific composition of the high-calorie diets containing L-fucose (Tokyo Chemical Industry, Tokyo, Japan) is shown in Table 1. The high-calorie diet was fed to induce obesity after adaptive feeding for one week. Obese mice were then randomly divided into six groups $(n=6)$ that were fed high-calorie diets containing $0.0001 \%, 0.001 \%, 0.01 \%$, or $0.1 \%$ L-fucose, and control diet for 30 days. The body weight of the mice was measured daily.

For the acute test, after adaptive feeding for one week, the mice were randomly divided into three groups: blank control, glucose, and L-fucose groups $(n=5)$. Mice were fasted overnight prior to the experiment while ensuring access to drinking water. At the beginning of the trial, the blank control, glucose, and L-fucose groups were administered $0.5 \mathrm{~mL}$ of distilled water, $4 \mathrm{mg} / \mathrm{mL}$ glucose, or $4 \mathrm{mg} / \mathrm{mL}$ L-fucose solution per individual, respectively, through a stainless-steel feeding needle.

The animal experimental design and study were performed following the institutional protocol approved by the University of Tokyo (\#P18-086H02). 
Table 1. The composition of high-calorie experimental diets ( $\mathrm{g} / \mathrm{kg}$ diet).

\begin{tabular}{cccccc}
\hline & Control & $\mathbf{0 . 0 0 0 1 \%}$ & $\mathbf{0 . 0 0 1 \%}$ & $\mathbf{0 . 0 1 \%}$ & $\mathbf{0 . 1 \%}$ \\
\hline Casein & 200 & 200 & 200 & 200 & 200 \\
$\alpha$-Cornstarch & 200 & 200 & 200 & 200 & 200 \\
$\beta$-Cornstarch & 96.25 & 96.249 & 96.24 & 96.15 & 95.25 \\
Sucrose & 100 & 100 & 100 & 100 & 100 \\
Cellulose & 50 & 50 & 50 & 50 & 50 \\
Soybean oil & 300 & 300 & 300 & 300 & 300 \\
AIN-93 mineral mix & 35 & 35 & 35 & 35 & 35 \\
AIN-93 vitamin mix & 10 & 10 & 10 & 10 & 10 \\
$50 \%$ choline chloride & 5 & 5 & 5 & 5 & 5 \\
L-Cystine & 3.75 & 3.75 & 3.75 & 3.75 & 3.75 \\
L-Fucose & - & 0.001 & 0.01 & 0.1 & 1 \\
\hline
\end{tabular}

\subsection{X-ray Scan}

In the chronic test, the visceral and liver fat amounts were measured once a week under continuous anesthesia with isoflurane (Wako Pure Chemical Industries, Tokyo, Japan) using a Latheta X-ray CT scanner (LCT-100, HITACHI, Tokyo, Japan). The X-ray CT images of the mice were obtained and analyzed using Latheta software v3.00 (HITACHI, Tokyo, Japan).

\subsection{Blood and Tissue Collection}

In the acute test, the blank control group was immediately sacrificed by cervical dislocation after oral administration with distilled water. The whole blood samples of mice belonging to the blank control group were collected from the heart. In the glucose and L-fucose groups, the animals were sacrificed by cervical dislocation after resuming feeding for $24 \mathrm{~h}$, and whole blood samples from both groups were collected from the heart. All whole-blood samples were left to clot at room temperature for $4 \mathrm{~h}$. The serum was separated from the clotted whole-blood samples by $3500 \mathrm{rpm}$ centrifugation at $4{ }^{\circ} \mathrm{C}$ for $15 \mathrm{~min}$ and stored at $-80^{\circ} \mathrm{C}$. The tissues (liver, skeletal muscle, and adipose) were collected after blood collection, soaked in RNA-later solution (Thermo Fisher Scientific Japan, Tokyo, Japan) at $4{ }^{\circ} \mathrm{C}$ for one day, and then used for total RNA extraction.

\subsection{Biochemical Analysis of Serum}

In the chronic test, mice were fasted overnight before blood collection. Whole blood was collected from the tail vein once a week. Fasting glucose levels were measured using a blood glucose meter (Glutest neo alpha, GT-1830; Arkray, Kyoto, Japan). Serum insulin was measured using a Mouse Insulin ELISA kit (FUJIFILM Wako Shibayagi, Gunma, Japan). The concentrations of serum total cholesterol (T-CHO) and non-esterified fatty acid (NEFA) were assayed using a 7180 Clinical Analyzer (HITACHI, Tokyo, Japan) in the $0.0001 \%, 0.001 \%, 0.01 \%$, and $0.1 \%$ L-fucose-administered and control groups.

\subsection{SDS-PAGE and Western Blotting}

Serum samples were subjected to electrophoresis on a sodium dodecyl sulfate polyacrylamide gel (SDS-PAGE, Multi gel II mini, CosmoBio, Tokyo, Japan) under non-reducing or reducing conditions. Serum samples were diluted 30-fold with $1 \times$ PBS and prepared in $4 \times$ Laemmli sample buffer (Bio-Rad, Tokyo, Japan) without (non-reducing) or with (reducing) dithiothreitol (DTT, $50 \mathrm{mM}$ ). Proteins were transferred to a low-fluorescence PVDF membrane (TransBlot Turbo, Bio-Rad, Tokyo, Japan) using a Trans-Blot Turbo Blotting System (Bio-Rad, Tokyo, Japan). After the transfer, the membrane was blocked with Tris-buffered saline (pH 7.4) containing 5\% BSA, $20 \mathrm{mM}$ Tris, and $150 \mathrm{mM} \mathrm{NaCl}$ (5\% BSA-TBS) at room temperature $\left(25^{\circ} \mathrm{C}\right)$ for $2 \mathrm{~h}$. After washing three times, the membrane was incubated at $4{ }^{\circ} \mathrm{C}$ overnight with the primary antibody (Rabbit Anti-Adiponectin 1:1000 v/v, Ab3455, Abcam, Tokyo, Japan). After washing three times with TBS supplemented with $0.1 \%$ Tween-20 (TBST), the membrane was incubated with a secondary antibody (Goat Anti-Rabbit IgG $(\mathrm{H}+\mathrm{L}), 1: 10,000 v / v$, Alexa Fluor 680, 
Abcam, Tokyo, Japan) at room temperature in the dark for $1 \mathrm{~h}$. Finally, after three washes with TBST, the fluorescence intensity of adiponectin was detected using a LI-COR Odyssey (LI-COR, Lincoln, NE, USA) imaging system.

\subsection{Total RNA Isolation}

Total RNA was extracted from mouse tissue samples (liver tissue $50 \mathrm{mg}$; adipose tissue $100 \mathrm{mg}$; skeletal muscle $50 \mathrm{mg}$ ) using an RNeasy Plus Universal Mini Kit (Qiagen, Tokyo, Japan) following the manufacturer's protocol. The purified total RNA was stored at $-80{ }^{\circ} \mathrm{C}$ until further use.

\subsection{Transcriptome Analysis}

Total RNA concentration and RNA integrity (RNA integrity number equivalent; RINe) from liver tissue were measured using a Qubit 2.0 fluorometer (Thermo Fisher Scientific, Tokyo, Japan) and an Agilent TapeStation 2200 System (Agilent Technologies, Tokyo, Japan). High-quality RNA samples were used for RNA-Seq analyses. The RNA-Seq analyses were performed by Eurofins Genomics (Eurofins Genomics, Tokyo, Japan) with eight groups of RNA samples (glucose and L-fucose oral administration group, four samples per group, diluted to $5.5 \mu \mathrm{g} / 55 \mu \mathrm{L}$ ) using a HiSeq2500 system (Illumina, San Diego, CA, USA). The original sequence reads were cleaned and mapped to the mouse genome gene reference (GRCm38.mm10) using QIAGEN's CLC Genomics Workbench v.11.0.1 (https://digitalinsights.qiagen.com/). Differentially expressed genes (DEGs) were identified between the glucose and L-fucose oral administration group using the reads per kilobase per million mapped reads (RPKM) values of corresponding transcripts. The filtering standard was set to more than a 1.5-fold change, and FDR $p$-value $\leq 0.05$. The DEGs containing up- and downregulated genes were used for gene ontology (GO)-term analysis using the Database for Annotation, Visualization, and Integrated Discovery (DAVID, https://david.ncifcrf.gov/) tools [23,24] for their functional classification.

\subsection{Quantitative Real-Time PCR}

Total RNA was reverse-transcribed was using a GeneAmp PCR System 9700 (Thermo Fisher Scientific, Tokyo, Japan) with a PrimeScript RT reagent Kit (TAKARA, Tokyo, Japan). RNA concentration was measured by UV spectrophotometry (NanoPhotometer P300, Implen, Germany). Then $2 \mu \mathrm{g}$ of total RNA from each sample was premixed with $1 \mu \mathrm{L}$ gDNA Eraser Genomic DNA and $2 \mu \mathrm{L} 5 \times$ gDNA Eraser Buffer. The pre-mixture was added to $10 \mu \mathrm{L}$ RNase-free water. Genomic DNA was eliminated at $42{ }^{\circ} \mathrm{C}$ for 2 min using a PCR system, premixing $1 \mu \mathrm{L}$ PrimeScript RT Enzyme Mix I, $4 \mu \mathrm{L} 5 \times$ PrimeScript Buffer 2, and $4 \mu \mathrm{L}$ RT Primer Mix. Then, $10 \mu \mathrm{L}$ of the solution from the elimination reaction was added to the pre-mixture. Reverse transcription was performed at $37^{\circ} \mathrm{C}$ for $15 \mathrm{~min}$, followed by a cycle at $85^{\circ} \mathrm{C}$ for $5 \mathrm{~s}$. The cDNA samples were stored at $-80^{\circ} \mathrm{C}$. TaqMan Gene Expression Assays (PPAR $\gamma$ : Mm00440940_m1,CD36: Mm00432403_m1, and $\beta$-actin: Mm00607939_s1, Thermo Fisher Scientific Japan, Tokyo, Japan) were diluted to $1 / 5$, and cDNA samples were diluted to 1/20 with nuclease-free water. Two microliters of cDNA samples were mixed with $1 \mu \mathrm{L}$ TaqMan Gene Expression Assay, $7 \mu \mathrm{L}$ nuclease-free water, and $10 \mu \mathrm{L}$ TaqMan Fast Advanced Master Mix. Subsequently, the mixtures were transferred to each well of a 96-well plate. The real-time PCR reaction was performed using the ABI PRISM 7300 system (Thermo Fisher Scientific Japan, Tokyo, Japan) with the following cycling conditions: $50{ }^{\circ} \mathrm{C}$ for $2 \mathrm{~min}, 95^{\circ} \mathrm{C}$ for $20 \mathrm{~s}$, followed by 40 cycles at $95^{\circ} \mathrm{C}$ for $3 \mathrm{~s}$, and $60{ }^{\circ} \mathrm{C}$ for $30 \mathrm{~s}$.

\subsection{Statistical Analysis}

All data are expressed as mean \pm standard error of the mean (SEM). Statistical analysis was performed using the GraphPad Prism 8 (v8.0.1) software. One-way analysis of variance (ANOVA) followed by Dunnett's multiple comparisons was used to detect the significance of the data. $p$-values $<0.05$ were considered statistically significant. 


\section{Results}

\subsection{L-Fucose Inhibits Body Weight and Liver Fat Mass Gains in High-Calorie Diet-Fed Mice}

In order to evaluate the effect of L-fucose on HCD-fed mice, we first performed body weight and X-ray scan tests in a one-month chronic experiment. In the chronic test, we found no significant difference in food intake between the control diet group and L-fucose-treated groups (data not shown). The body weight of mice increased gradually in all groups. The statistical analysis showed that the weight gain was significantly lower in the $0.001 \%, 0.01 \%$, and $0.1 \%$ L-fucose groups than in the control group over the tested period, especially in the $0.1 \%$ L-fucose group (Figure $1 \mathrm{~A}$ ). The X-ray CT scan results showed that the visceral fat weight of the $0.1 \%$ and $0.01 \% \mathrm{~L}$-fucose-administered groups was significantly lower than that of the control group on days 9 and 25 (Figure 1B). However, the liver fat mass of mice remained nearly unchanged (Figure 1C). There was no significant difference between the L-fucose treatment group and control in the fasting glucose and insulin levels (Supplementary Figure S1A,B). Although we observed that the total cholesterol level in the $0.1 \%$ L-fucose group was significantly lower than in the control group on day 21, we found no major change for other fucose treatment groups in the serum total cholesterol and NEFA levels (Supplementary Figure S2A,B).
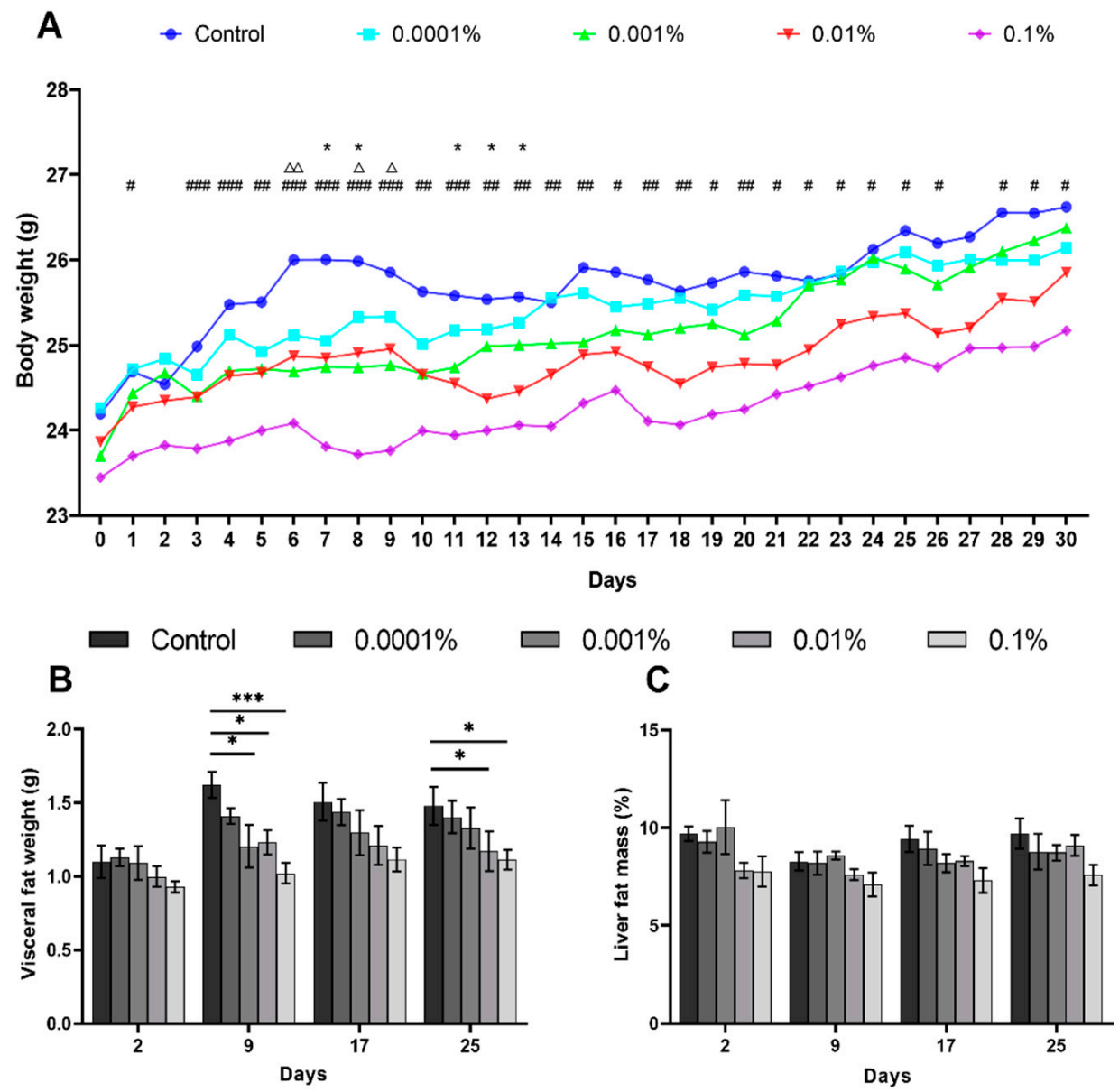

Figure 1. L-Fucose suppresses fat accumulation in high-calorie diet-induced obese mice. (A) Body weight gains in high-calorie diet-induced obese mice $(n=6)$ fed either a control high-calorie or high-calorie diet with $0.0001 \%, 0.001 \%, 0.001 \%$ and $0.1 \%$ L-fucose form day 0 to 30 ( $\triangle$ [Control vs. $0.001 \%$ ], * [Control vs. 0.01\%], \# [Control vs. 0.1\%]: $\left.p<0.05 ; \Delta \triangle, \# \#: p<0.01 ;{ }^{* * *}, \# \# \#: p<0.001\right)$. (B) Visceral fat weight and (C) liver fat mass of mice detected by CT-scan (Day 2, 9, 17, 25, * $p<0.05$, ***: $p<0.001)$. 


\subsection{L-Fucose Promotes Adiponectin Multimerization}

Serum adiponectin levels in mice were detected using Western blotting. Total adiponectin (30 kDa) levels were confirmed in the reducing condition (Figure 2A). The levels of total adiponectin were reduced by the L-fucose acute administration after $24 \mathrm{~h}$ (Figure 2B). In the non-reducing condition, we detected three different molecular weight bands: high molecular weight (HMW, $\sim 300 \mathrm{kDa}$ ), medium molecular weight (MMW, $\sim 140 \mathrm{kDa}$ ), and low molecular weight (LMW, $\sim 67 \mathrm{kDa}$ ) of adiponectin (Figure 2C). Initially, the mean HMW adiponectin ratio was 23.2\% (SEM 0.0088). After $24 \mathrm{~h}$ of acute oral administration of L-fucose, the values of HMW adiponectin in the L-fucose-administered group tended to increase. The mean serum HMW adiponectin ratios in the glucose and L-fucose groups were 25.4\% (SEM 0.020) and 33.3\% (SEM 0.011), respectively (Figure 2D). The serum HMW adiponectin ratio in the L-fucose group was significantly higher than in the glucose group $(p<0.01)$.
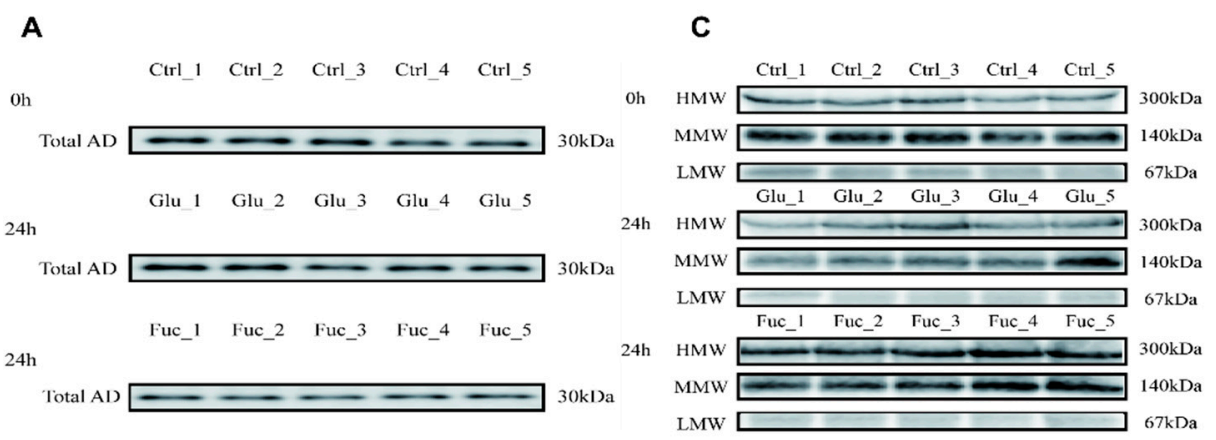

$\mathbf{B}$

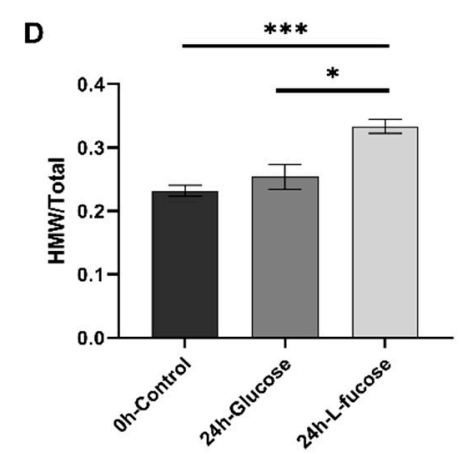

Figure 2. L-Fucose decreases the total adiponectin and changes the composition of multimeric serum adiponectin. (A) Western blot analysis of total adiponectin protein levels from serum of acute glucose and L-fucose-fed mice. (Total AD: total adiponectin, $30 \mathrm{kDa}, n=5$ ). (B) Relative intensity of total serum adiponectin. (C) Western blot analysis of multimeric adiponectin protein levels from serum of acute glucose and L-fucose-administered mice (HMW: high molecular weight, $300 \mathrm{kDa}$; MMW: medium molecular weight, $\sim 140 \mathrm{kDa}$; LMW: low molecular weight, $\sim 67 \mathrm{kDa}, n=5)$. (D) Ratio of serum HMW adiponectin to total adiponectin $\left(^{*}: p<0.05,{ }^{* *}: p<0.01^{* * *}: p<0.001\right)$.

\subsection{L-Fucose Enhances Glucose and Lipid Catabolism}

High-throughput sequence data of eight samples from the liver (glucose and L-fucose treatment groups, four samples each) were generated using HiSeq2500. These reads were further analyzed using the CLC Genomics Workbench v.11.0.1, and the GRCm38 (mm10) reference gene set was chosen for mapping. The gene expression levels of each identified gene are represented as RPKM. At $24 \mathrm{~h}$ we identified DEGs in the liver tissue with a significant difference in the L-fucose group compared to the glucose group. We obtained a total of 96 DEGs from the analyses with fold change $>1.5$, and $p$-value $\leq 0.05$ (Figure 3A). The up- or downregulated genes were uploaded to the DAVID (https://david.ncifcrf.gov/) to analyze gene-annotation enrichment. The upregulated genes in L-fucose group compared to glucose group were enriched in sequences linked to biological processes related to insulin secretion, glucose and lipid catabolism, and lipid storage. The downregulated genes were 
instead enriched in sequences linked to biological processes related to the steroid hormone stimulus and cell growth (Figure 3B).

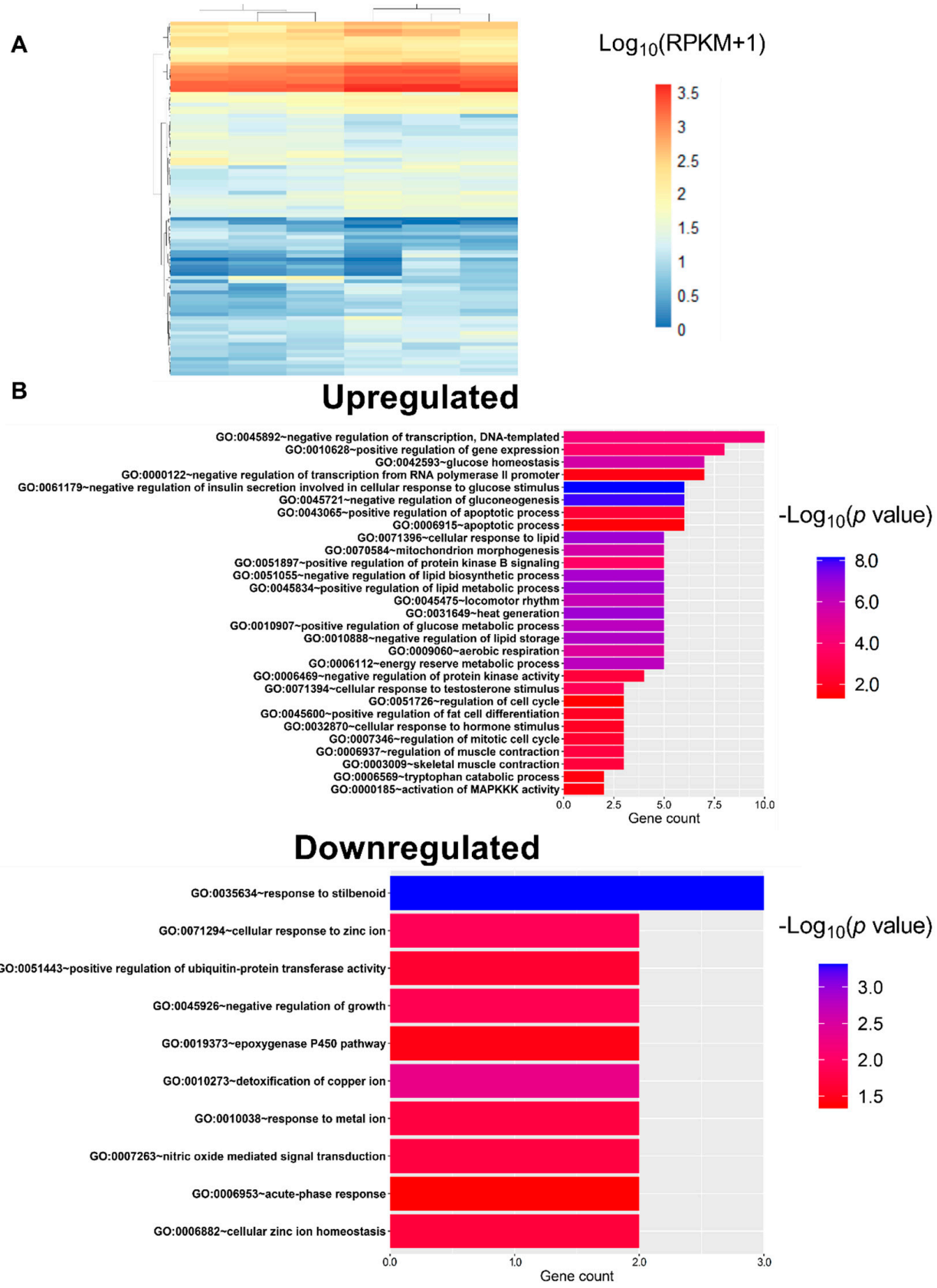

Figure 3. L-Fucose affects the energy metabolism of mice. (A) Heat map of expression values of DEGs between acute glucose and L-fucose-treated mice. Every sample correspond to a column, and every DEG to a row. DEGs were clustered by $\log _{10}(R P K M+1)$ value, orange indicates highly expressed genes, blue indicates genes with lower expression. (B) Enrichment of GO biological processes terms using DEGs detected by DAVID. The ordinate shows the enriched GO term, and the abscissa shows the enriched differential gene count in the GO term. The $-\log _{10}(p$ value) was used to measure the significance.

\subsection{L-Fucose Decreases the Gene Expression of Lipid Metabolism-Related Genes}

Having observed the effect of L-fucose on lipid metabolism by transcriptome analysis, we next analyzed the topic genes using quantitative real-time PCR to determine whether L-fucose could affect 
adipogenic gene expression. We determined the relative expression levels of lipid metabolism-related genes (PPAR $\gamma$ and CD36) from skeletal muscle, liver, and adipose tissues. After 24 h of oral glucose administration, the expression of PPAR $\gamma$ and CD36 genes in the liver increased. The expression of PPAR $\gamma$ and CD36 genes was significantly lower $(p<0.05)$ after L-fucose administration compared with glucose administration (Figure $4 \mathrm{~A}$ ). In the skeletal muscle, PPAR $\gamma$ gene expression levels showed a decreasing trend over time in both the glucose and L-fucose groups (Figure 4B), but no difference was observed in CD36 gene expression levels. Finally, in the adipose tissue, the gene expression of PPAR $\gamma$ in the L-fucose group tended to be lower than in the glucose group after $24 \mathrm{~h}$ of treatment, while we observed no effect on CD36 gene expression (Figure 4C).

A

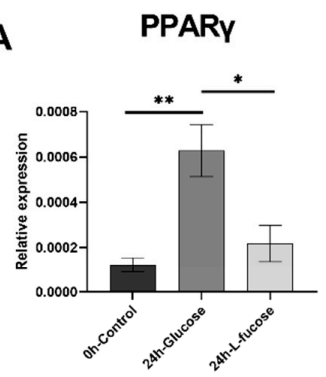

C

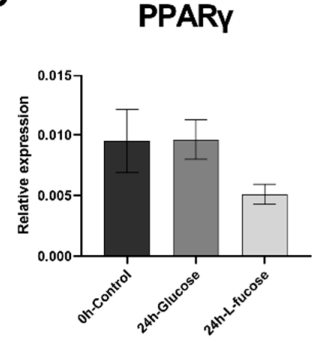

CD36

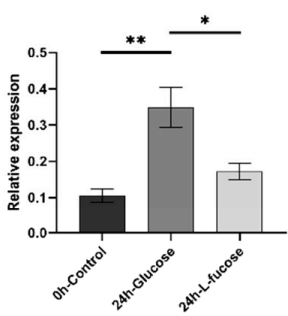

CD36

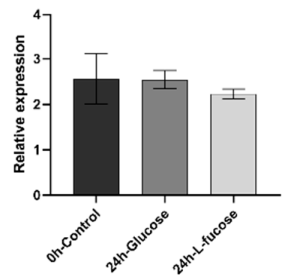

B

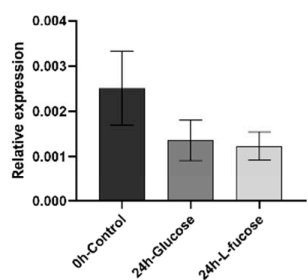

CD36

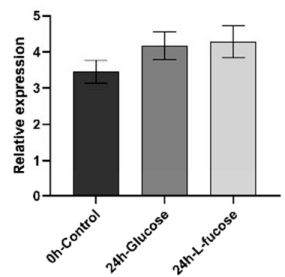

Figure 4. L-Fucose decreases the expression of adipogenic genes. Relative expression of PPAR $\gamma$ and CD36 in (A) liver, (B) skeletal muscle, and (C) adipose tissue of glucose and L-fucose-treated mice $\left({ }^{*}: p<0.05,{ }^{* *}: p<0.01\right.$, The relative mRNA levels are expressed as the mean $2^{-\Delta \Delta \mathrm{Ct}}$ relative to the control $\beta$-actin).

\section{Discussion}

In the present study, we confirmed the anti-obesity effect of L-fucose using long-term chronic tests and determined the possible molecular mechanisms using acute tests in mice. Our results showed that L-fucose suppressed body weight and liver fat mass gain in HCD-induced obese mice, increasing the ratio of serum HMW adiponectin. Furthermore, it enhanced lipid catabolism and decreased lipid metabolism-related gene expression.

The HMW/total adiponectin ratio has been reported as a useful biomarker to predict metabolic syndrome $[25,26]$. Here, L-fucose promoted the multimerization of adiponectin, which reduces the risk of metabolic syndrome-related morbidities such as non-alcoholic fatty liver disease (NAFLD) [27]. While L-fucose might further activate the AMPK signaling pathway to enhance insulin sensitivity and stimulate fatty acid oxidation [28], here, L-fucose had no effect on serum glucose levels and insulin resistance, consistent to with the results from a previous study [18]. Our results also showed that L-fucose promoted the biological processes related to lipid and glucose consumption such as lipolysis and glycolysis, and inhibited lipogenesis. Thus, obesity can be counteracted by reducing energy production and increasing energy expenditure.

$\operatorname{PPAR} \gamma$, an adipogenic marker protein, is a ligand-activated nuclear hormone receptor, that exerts critical regulatory roles in adipogenesis [12]. PPAR $\gamma$ has been identified as a target for obesity treatment [29]. CD36 is a membrane glycoprotein belonging to the class B scavenger receptor family 
which is expressed in platelets, mononuclear phagocytes, adipocytes, hepatocytes, myocytes, and some epithelial cells [13]. As a fatty acid translocase, CD36 plays a crucial role in lipid transport and metabolism [30]. PPAR $\gamma$ regulates the gene expression of CD36 in the liver, muscle, and adipose tissue, and CD36 is generally used as a reporter gene of PPAR $\gamma$ [31-33]. Berberine, an isoquinoline alkaloid inhibits the expression of adiponectin through the inhibition of PPAR $\gamma$ transcriptional activity and promotes the multimerization of adiponectin [34], thus reducing adipose tissue mass [35]. The present results are consistent with those reported for berberine. Our findings suggest that L-fucose may prevent adipogenesis by inhibiting of PPAR $\gamma$ activity and stimulate fatty acid oxidation by promoting adiponectin multimerization. Furthermore, the reduction in PPAR $\gamma$ expression would result in a decrease in total serum adiponectin. The increased energy consumption, via heat generation and lipid catabolism, leads to increase fat consumption and reduce fat accumulation. The combination of decreased fat synthesis and increased fat consumption reduces the amount of fat accumulated. However, we found that L-fucose did not affect serum glucose and insulin levels. A possible explanation is that the effects on glucose may be L-fucose dose-dependent and therefore require further investigation with high-dose treatment.

L-Fucose is a monosaccharide obtained from the brown algae polysaccharide, fucoidan, which can be easily extracted from brown algae [36]. It is also considered safe for human oral administration [21]. Recently, L-fucose has been reported to ameliorate high-fat diet-induced obesity and influence the function of intestinal flora in C57BL/6 mice. However, the specific molecular mechanism has not yet been reported [18]. In this study, we demonstrated the effects of L-fucose on the transcriptional levels of lipid-related genes in C57BL/6 mice. L-Fucose might promote the multimerization of adiponectin, increase energy consumption, and reduce fat accumulation. Although the present results suggest that L-fucose could be used as a dietary supplement to prevent obesity, further studies are needed to validate this finding.

While the current study confirmed the transcriptional effects of L-fucose in mice, there are some limitations as well. First, in our study, the effects on body weight and liver fat content of L-fucose were observed after chronic administration, whereas the effects on the transcriptional effects of L-fucose were observed after an acute administration. Thus, we cannot exclude the possibility that other factors might be determinants for obesity prevention. Second, the mechanism underlying the increase in HMW adiponectin is still unclear. Previous studies have shown that adiponectin glycosylation affects the stability of HMW and MMW complexes [37-40]. L-Fucose might in fact affect adiponectin glycosylation. Further studies should be carried out to confirm the anti-obesity effect and safety of L-fucose. In conclusion, our results provide a basis for the application of brown algae-derived L-fucose for obesity-related disease prevention, but more detailed clinical validation studies are needed.

Supplementary Materials: The following are available online at http://www.mdpi.com/2072-6643/12/12/3798/s1, Figure S1. Fasting serum glucose (A), and fasting serum insulin (B); Figure S2. Serum levels of total cholesterol (A) and non-esterified fatty acids (B).

Author Contributions: Conceptualization, X.Y. and H.U.; methodology, X.Y., T.N., H.S., K.O., Y.K. and H.U.; software, X.Y. and H.U.; validation, X.Y. and H.U.; investigation, X.Y. and H.U.; writing-original draft preparation, X.Y.; writing-review and editing, X.Y., Y.K., M.I., T.A., T.U. and H.U.; supervision, H.U.; project administration, T.U. and H.U.; funding acquisition, T.A., T.U. and H.U. All authors have read and agreed to the published version of the manuscript.

Funding: This research was funded in part by the Japan Science and Technology Agency (JST), Adaptable and Seamless Technology transfer Program through Target-driven R\&D (A-STEP), grant number JPMJTR194E.

Conflicts of Interest: The authors declare the conflict of interest.

\section{References}

1. Snijder, M.; Zimmet, P.Z.; Visser, M.; Dekker, J.; Seidell, J.; Shaw, J.E. Independent and opposite associations of waist and hip circumferences with diabetes, hypertension and dyslipidemia: The AusDiab Study. Int. J. Obes. 2004, 28, 402-409. [CrossRef]

2. Calle, E.E.; Thun, M.J. Obesity and cancer. Oncogene 2004, 23, 6365-6378. [CrossRef] 
3. De Oliveira Leal, V.; Mafra, D. Adipokines in obesity. Clin. Chim. Acta 2013, 419, 87-94. [CrossRef] [PubMed]

4. Kubota, N.; Yano, W.; Kubota, T.; Yamauchi, T.; Itoh, S.; Kumagai, H.; Kozono, H.; Takamoto, I.; Okamoto, S.; Shiuchi, T.; et al. Adiponectin stimulates AMP-activated protein kinase in the hypothalamus and increases food intake. Cell Metab. 2007, 6, 55-68. [CrossRef] [PubMed]

5. Corton, J.M.; Gillespie, J.G.; Hardie, D.G. Role of the AMP-activated protein kinase in the cellular stress response. Curr. Biol. 1994, 4, 315-324. [CrossRef]

6. Yamauchi, T.; Kamon, J.; Waki, H.; Terauchi, Y.; Kubota, N.; Hara, K.; Mori, Y.; Ide, T.; Murakami, K.; Tsuboyama-Kasaoka, N. The fat-derived hormone adiponectin reverses insulin resistance associated with both lipoatrophy and obesity. Nat. Med. 2001, 7, 941-946. [CrossRef]

7. Waki, H.; Yamauchi, T.; Kamon, J.; Ito, Y.; Uchida, S.; Kita, S.; Hara, K.; Hada, Y.; Vasseur, F.; Froguel, P. Impaired multimerization of human adiponectin mutants associated with diabetes molecular structure and multimer formation of adiponectin. J. Biol. Chem. 2003, 278, 40352-40363. [CrossRef] [PubMed]

8. Pajvani, U.B.; Du, X.; Combs, T.P.; Berg, A.H.; Rajala, M.W.; Schulthess, T.; Engel, J.; Brownlee, M.; Scherer, P.E. Structure-function studies of the adipocyte-secreted hormone Acrp30/adiponectin implications for metabolic regulation and bioactivity. J. Biol. Chem. 2003, 278, 9073-9085. [CrossRef] [PubMed]

9. Wang, Y.; Lam, K.S.; Yau, M.-h.; Xu, A. Post-translational modifications of adiponectin: Mechanisms and functional implications. Biochem. J. 2008, 409, 623-633. [CrossRef] [PubMed]

10. Eckel, R.H.; Grundy, S.M.; Zimmet, P.Z. The metabolic syndrome. Lancet 2005, 365, 1415-1428. [CrossRef]

11. Lara-Castro, C.; Luo, N.; Wallace, P.; Klein, R.L.; Garvey, W.T. Adiponectin multimeric complexes and the metabolic syndrome trait cluster. Diabetes 2006, 55, 249-259. [CrossRef]

12. Tyagi, S.; Gupta, P.; Saini, A.S.; Kaushal, C.; Sharma, S. The peroxisome proliferator-activated receptor: A family of nuclear receptors role in various diseases. J. Adv. Pharm. Technol. Res. 2011, 2, 236. [CrossRef] [PubMed]

13. Febbraio, M.; Hajjar, D.P.; Silverstein, R.L. CD36: A class B scavenger receptor involved in angiogenesis, atherosclerosis, inflammation, and lipid metabolism. J. Clin. Investig. 2001, 108, 785-791. [CrossRef] [PubMed]

14. Wijesekara, I.; Pangestuti, R.; Kim, S.-K. Biological activities and potential health benefits of sulfated polysaccharides derived from marine algae. Carbohydr. Polym. 2011, 84, 14-21. [CrossRef]

15. Li, B.; Lu, F.; Wei, X.; Zhao, R. Fucoidan: Structure and bioactivity. Molecules 2008, 13, 1671-1695. [CrossRef]

16. Kim, M.J.; Jeon, J.; Lee, J.S. Fucoidan prevents high-fat diet-induced obesity in animals by suppression of fat accumulation. Phytother. Res. 2014, 28, 137-143. [CrossRef]

17. Kim, M.J.; Chang, U.J.; Lee, J.S. Inhibitory effects of fucoidan in 3T3-L1 adipocyte differentiation. Mar. Biotechnol. 2009, 11, 557-562. [CrossRef]

18. Wu, G.; Niu, M.; Tang, W.; Hu, J.; Wei, G.; He, Z.; Chen, Y.; Jiang, Y.; Chen, P. L-Fucose ameliorates high-fat diet-induced obesity and hepatic steatosis in mice. J. Transl. Med. 2018, 16, 1-12. [CrossRef]

19. Coffey, J.; Miller, O.N.; Sellinger, O.Z. The metabolism of L-fucose in the rat. J. Biol. Chem. 1964, 239, 4011-4017.

20. Ale, M.T.; Mikkelsen, J.D.; Meyer, A.S. Important determinants for fucoidan bioactivity: A critical review of structure-function relations and extraction methods for fucose-containing sulfated polysaccharides from brown seaweeds. Mar. Drugs 2011, 9, 2106-2130. [CrossRef]

21. Choi, S.S.; Lynch, B.S.; Baldwin, N.; Dakoulas, E.W.; Roy, S.; Moore, C.; Thorsrud, B.A.; Röhrig, C.H. Safety evaluation of the human-identical milk monosaccharide, 1-fucose. Regul. Toxicol. Pharmacol. 2015, 72, $39-48$. [CrossRef] [PubMed]

22. Hong, J.; Stubbins, R.E.; Smith, R.R.; Harvey, A.E.; Núñez, N.P. Differential susceptibility to obesity between male, female and ovariectomized female mice. Nutr. J. 2009, 8, 11. [CrossRef] [PubMed]

23. Huang, D.W.; Sherman, B.T.; Lempicki, R.A. Bioinformatics enrichment tools: Paths toward the comprehensive functional analysis of large gene lists. Nucleic Acids Res. 2009, 37, 1-13. [CrossRef] [PubMed]

24. Huang, D.W.; Sherman, B.T.; Lempicki, R.A. Systematic and integrative analysis of large gene lists using DAVID bioinformatics resources. Nat. Protoc. 2009, 4, 44-57. [CrossRef] [PubMed]

25. Seino, Y.; Hirose, H.; Saito, I.; Itoh, H. High molecular weight multimer form of adiponectin as a useful marker to evaluate insulin resistance and metabolic syndrome in Japanese men. Metabolism 2007, 56, 1493-1499. [CrossRef] 
26. Hara, K.; Horikoshi, M.; Yamauchi, T.; Yago, H.; Miyazaki, O.; Ebinuma, H.; Imai, Y.; Nagai, R.; Kadowaki, T. Measurement of the high-molecular weight form of adiponectin in plasma is useful for the prediction of insulin resistance and metabolic syndrome. Diabetes Care 2006, 29, 1357-1362. [CrossRef]

27. Finelli, C.; Tarantino, G. What is the role of adiponectin in obesity related non-alcoholic fatty liver disease? World J. Gastroenterol. 2013, 19, 802. [CrossRef] [PubMed]

28. Achari, A.E.; Jain, S.K. Adiponectin, a therapeutic target for obesity, diabetes, and endothelial dysfunction. Int. J. Mol. Sci. 2017, 18, 1321. [CrossRef]

29. Lefterova, M.I.; Haakonsson, A.K.; Lazar, M.A.; Mandrup, S. PPAR $\gamma$ and the global map of adipogenesis and beyond. Trends Endocrinol. Metab. 2014, 25, 293-302. [CrossRef]

30. Bieghs, V.; Wouters, K.; Van Gorp, P.J.; Gijbels, M.J.; De Winther, M.P.; Binder, C.J.; Lütjohann, D.; Febbraio, M.; Moore, K.J.; Van Bilsen, M. Role of scavenger receptor A and CD36 in diet-induced nonalcoholic steatohepatitis in hyperlipidemic mice. Gastroenterology 2010, 138, 2477-2486. [CrossRef]

31. Zhou, J.; Febbraio, M.; Wada, T.; Zhai, Y.; Kuruba, R.; He, J.; Lee, J.H.; Khadem, S.; Ren, S.; Li, S. Hepatic fatty acid transporter Cd36 is a common target of LXR, PXR, and PPAR $\gamma$ in promoting steatosis. Gastroenterology 2008, 134, 556-567. [CrossRef]

32. Bonen, A.; Campbell, S.E.; Benton, C.R.; Chabowski, A.; Coort, S.L.; Han, X.X.; Koonen, D.P.; Glatz, J.F.; Luiken, J.J. Regulation of fatty acid transport by fatty acid translocase/CD36. Proc. Nutr. Soc. 2004, 63, 245-249. [CrossRef]

33. Chawla, A.; Barak, Y.; Nagy, L.; Liao, D.; Tontonoz, P.; Evans, R.M. PPAR-gamma dependent and independent effects on macrophage-gene expression in lipid metabolism and inflammation. Nat. Med. 2001, 7, 48-52. [CrossRef]

34. Li, Y.; Wang, P.; Zhuang, Y.; Lin, H.; Li, Y.; Liu, L.; Meng, Q.; Cui, T.; Liu, J.; Li, Z. Activation of AMPK by berberine promotes adiponectin multimerization in 3T3-L1 adipocytes. FEBS Lett. 2011, 585, 1735-1740. [CrossRef]

35. Lee, Y.S.; Kim, W.S.; Kim, K.H.; Yoon, M.J.; Cho, H.J.; Shen, Y.; Ye, J.-M.; Lee, C.H.; Oh, W.K.; Kim, C.T. Berberine, a natural plant product, activates AMP-activated protein kinase with beneficial metabolic effects in diabetic and insulin-resistant states. Diabetes 2006, 55, 2256-2264. [CrossRef] [PubMed]

36. Ale, M.T.; Mikkelsen, J.D.; Meyer, A.S. Designed optimization of a single-step extraction of fucose-containing sulfated polysaccharides from Sargassum sp. J. Appl. Phycol. 2012, 24, 715-723. [CrossRef]

37. Peake, P.W.; Hughes, J.T.; Shen, Y.; Charlesworth, J.A. Glycosylation of human adiponectin affects its conformation and stability. J. Mol. Endocrinol. 2007, 39, 45-52. [CrossRef] [PubMed]

38. Richards, A.A.; Stephens, T.; Charlton, H.K.; Jones, A.; Macdonald, G.A.; Prins, J.B.; Whitehead, J.P. Adiponectin multimerization is dependent on conserved lysines in the collagenous domain: Evidence for regulation of multimerization by alterations in posttranslational modifications. Mol. Endocrinol. 2006, 20, 1673-1687. [CrossRef] [PubMed]

39. Richards, A.A.; Colgrave, M.L.; Zhang, J.; Webster, J.; Simpson, F.; Preston, E.; Wilks, D.; Hoehn, K.L.; Stephenson, M.; Macdonald, G.A. Sialic acid modification of adiponectin is not required for multimerization or secretion but determines half-life in circulation. Mol. Endocrinol. 2010, 24, 229-239. [CrossRef] [PubMed]

40. Wang, Y.; Lam, K.S.; Chan, L.; Chan, K.W.; Lam, J.B.; Lam, M.C.; Hoo, R.C.; Mak, W.W.; Cooper, G.J.; Xu, A. Post-translational modifications of the four conserved lysine residues within the collagenous domain of adiponectin are required for the formation of its high molecular weight oligomeric complex. J. Biol. Chem. 2006, 281, 16391-16400. [CrossRef]

Publisher's Note: MDPI stays neutral with regard to jurisdictional claims in published maps and institutional affiliations.

(C) 2020 by the authors. Licensee MDPI, Basel, Switzerland. This article is an open access article distributed under the terms and conditions of the Creative Commons Attribution (CC BY) license (http://creativecommons.org/licenses/by/4.0/). 